\title{
Optimalisasi Media Penyimpanan pada Sistem Inventori Stok Barang untuk PT. Multi Usaha Sejahtera Jaya menggunakan Metode Goldbach Codes
}

\author{
Angga Debby Frayudha ${ }^{1}$, Siti Purwanti ${ }^{1}$ \\ ${ }^{1}$ Otomasi Perkantoran, Akademi Komunitas Semen Indonesia Rembang \\ E-mail: mpyenk@gmail.com
}

\begin{abstract}
Conventional data management, both manuals on books and the use of data processing applications (words or numbers) are considered to have limitations, especially in terms of affordability of access and management. The inventory information system is able to provide data management in the form of information needed for the productivity of the business premises according to the characteristics of the information users at the place of business. Furthermore, for a better data transmission process, it is necessary to optimize the storage media through certain data compression techniques. One of the text data compression algorithms that has the advantage of optimizing the size of the compression results is Goldbach Codes. This article describes the development of an inventory management system with the ability to store and modify data on stock items, sales, purchases and reports that have optimal data efficiency. In this study, using the Research and Development method with 7 stages in the form of: 1) potential problems, 2) data collection, 3) product design, 4) design validation, 5) product testing, 6) product revision, 7) usage testing. The results of application testing get a feasibility percentage of $83 \%$ from media experts (IT), 85\% from small-scale users (PT Multi Usaha Sejahtera). It can be concluded that the media being developed is "very feasible". The advantages of the proposed system are faster and paperless data search. This research can be used as a basis for related research. The aspect that needs to be considered in future research is the acceptability of the information system.
\end{abstract}

Keywords: Inventory System, Stock of Goods, PHP, MYSQL, Goldbach Codes

\begin{abstract}
ABSTRAK
Pengelolaan data secara konvensional, baik manual pada buku maupun penggunaan aplikasi pengolah data (kata atau angka) dinilai masih memiliki keterbatasan terutama dalam hal keterjangkauan akses dan pengelolaan. Sistem informasi inventori mampu menyajikan pengelolaan data berupa informasi-informasi yang dibutuhkan untuk produktivitas tempat usaha sesuai karakteristik pengguna informasi pada tempat usaha tersebut. Lebih lanjut untuk proses transmisi data yang lebih baik, diperlukan optimalisasi media penyimpanan melalui teknik kompresi data tertentu. Salah satu algoritma kompresi data teks yang memiliki keunggulan pada optimalisasi ukuran hasil kompresi adalah Goldbach Codes. Artikel ini mendeskripsikan pengembangan sistem pengelolaan inventori dengan kemampuan dapat menyimpan maupun mengubah data stok barang, penjualan, pembelian barang dan laporannya yang memiliki efisiensi data yang optimal. Dalam penelitian ini menggunakan metode Riset and Development dengan 7 tahapan berupa: 1) potensi masalah, 2) pengumpulan data, 3) desain produk, 4) validasi desain, 5) uji coba produk, 6) revisi produk, 7) uji coba pemakaian. Hasil dari pengujian aplikasi mendapatkan presentase kelayakan sebesar 83\% dari ahli media (IT), 85\% dari pengguna skala kecil (PT Multi Usaha Sejahtera). Dapat disimpulkan bahwa media yang dikembangkan "sangat layak". Kelebihan dari sistem yang diusulkan adalah pencarian data semakin cepat dan paperless. Penelitian ini dapat dijadikan pijakan untuk penelitian terkait. Aspek yang perlu dipertimbangkan pada penelitian ke depan adalah aspek keberterimaan sistem informasi.
\end{abstract}

Kata kunci: Sistem Inventori, Persediaan barang, PHP, MySQL, Goldbach Codes

\section{PENDAHULUAN}

Penyimpanan informasi dan dokumen secara konvensional dilakukan dengan pencatatan pada buku tertentu. Terdapat faktor resiko rusak dan hilangnya data pada buku tersebut. Perkembangan teknologi informasi menjadi pilihan metode penyelesaian tugas. Pendataan dilakukan dengan pencataan di aplikasi pengolah kata misalnya atau pengolah angka. Pendataan tersebut, menghasilkan data relatif lebih aman, akan tetapi keterjangkauan informasi terbatas. Untuk meningkatkan keterjangkauan informasi tersebut maka Teknologi Informasi dan Komunikasi (TIK) memiliki peran yang strategis bagi dunia usaha. Peran strategis yang dimaksud adalah membantu 
pengelolaan data menjadi lebih terstruktur yang membantu kinerja manajemen juga mampu meningkatkan efektifitas, produktivitas dan daya saing suatu usaha dalam dunia usaha. Informasiinformasi pada aplikasi pengolah data disusun terpisah atau tidak terintegrasi dengan baik. Ketika semua informasi diperlukan akan menyebabkan kendala karena semua tabel data informasi yang ada harus dibuka satu demi satu [1]. Keterbatasan lain adalah kesulitan pencarian data, keterlambatan pelaporan, kesulitan dalam penyimpanan data apabila data berbentuk berkas, dan kebutuhan media penyimpanan besar akibat data berupa berkas [2]. Kendala lain dari pendataan dengan pengolah angka adalah waktu yang lama dalam pendataan dan ketidakakuratan dalam pelaporan dikarenakan kerumitan struktur data [3]. Secara spesifik, pada tempat usaha, kesulitan dalam mendapatkan informasi mengenai persediaan barang dan pelaporan menjadi penghambat [4]. Penerapan TIK pada dunia usaha tersebut perlu dioptimalkan.

Persaingan usaha dalam dunia usaha menjadi ketat seiring dengan kemajuan perkembangan TIK. Jumlah perusahaan semakin banyak dan terus melakukan usaha dan strategi dalam mempertahankan bisnisnya. Kesuksesan perusahaan dalam mempertahankan bisnisnya tidak terlepas dari peran perusahaan tersebut dalam mengelola persediaan (inventory) barang. Pengelolaan persediaan barang yang baik dapat memenuhi permintaan dari pelanggan dan tentu saja dapat menjaga kelangsungan bisnisnya dalam dunia industri saat ini. Pencarian informasi mengenai persediaan barang, pelacakan transaksi barang dan pelaporan barang dapat secara manual maupun pencatatan pada excel tidak dapat menunjang sirkulasi barang yang cepat dan akurat. Hal tersebut dapat menghambat usaha yang dijalankan.

Pengelolaan persediaan barang di dalam suatu usaha menjadi hal yang penting bagi suatu perusahaan. Karena dari pengelolaan persediaan tersebut bisa mengelola stok barang di gudang yang nantinya akan dijual ke konsumen. Persediaan adalah suatu jenis aktiva atau barang yang dimiliki oleh suatu perusahaan atau badan usaha tertentu, yang akan dijual kembali atau akan dikonsumsi dalam operasi normal perusahaan. persediaan adalah pos harta yang ditahan untuk dijual dalam kegiatan usaha yang biasa atau barang yang dikonsumsi dalam produksi barang yang akan dijual [5].

Pemanfaatan sistem informasi dapat digunakan dalam pengelolaan berbagai data, termasuk dalam hal ini dalah pengelolaan persediaan barang pada suatu usaha. Sistem inventori merupakan sekumpulan kebijakan dan pengendalian barang terkait barang masuk dan keluar [6]. Sistem pengelolaan persediaan memiliki karakteristik dengan fitur-fitur yang berbeda sesuai kebutuhan pemilik usaha. Hal tersebut sejalan dengan Sohail dan Sheikh, bahwa inventori adalah aset dengan fitur yang berbeda [7]. Kebutuhan informasi yang perlu dikelola pada suatu usaha berbeda-beda. Informasi-informasi yang dimaksud tersebut memiliki karakter untuk peningkatan produktivitas tempat usaha. Karakter lainnya adalah terkait jenis pengguna yang memanfaatkan informasi tersebut. Oleh karena itu dalam sistem pengelolaan inventori perlu dianalisis dengan baik terkait karakteristik informasi dan pengguna informasi.

Kapasitas simpan pada media penyimpanan memiliki keterbatasan. Sistem pengelolaan persediaan diharapkan tidak terlalu membebani media penyimpanan. Penggunaan cloud storage untuk menjangkau data menjadi salah satu alternatif untuk tidak membebani media penyimpanan [8]. Diperlukan suatu algoritma tertentu untuk memberikan optimalisasi media penyimpanan pada sistem pengelolaan persediaan yang dikembangkan. Salah satu teknik yang digunakan untuk optimalisasi tersebut adalah kompresi data.

Kompresi merupakan efisiensi kebutuhan media penyimpanan data dan waktu pengiriman data dengan melakukan pengubahan data yang berbentuk kumpulan karakter menjadi bentuk kode tertentu [9]. Kebutuhan sumber daya terkait ukuran memori dan kecepatan PC, kecepatan kompresi, ukuran file hasil kompresi, besarnya 
redundansi dan kompleksitas pada algoritma kompresi menjadi pertimbangan yang digunakan pengembang untuk melakukan pemilihan algoritma kompresi data [9]. Kompresi data teks diantaranya dapat dilakukan dengan Algoritma Lempel-ZIV-Welch dengan Fibonacci Search. Akan tetapi algoritma tersebut memiliki keterbattasan dalam hal pengurutan data pada kamus data yang memerlukan waktu tambahan [10]. Strategi lainnya adalah penyimpanan data dalam bentuk XML (Extensible Markup Language) [11]. Algoritma lain adalah Goldbach Codes yang mampu mengoptimalkan media penyimpanan pada memori berupa file text [12] dan file gambar [13]. Algoritma Goldbach Codes melakukan kompresi file text disbanding algoritma Dynamic Markov Compression [14]. Artikel ini menggunakan algoritma Goldbach Codes dikarenakan optimal dalam ukuran hasil kompresi.

Algoritma Goldbach Codes adalah algoritma yang di asumsikan untuk memaksimalkan penyimpanan pada aplikasi inventory stok menggunakan teori Goldbach Conjecture, denga memanfaatkan algoritma tersebut diharapkan jumlah memori penyimpanan pada aplikasi bisa lebih maksimal dalam menyimpan file. Algoritma digunakan untuk kompresi data agar penggunaan memori tidak begitu menggunakan memori penyimpanan terlalu banyak pada aplikasi. Pada Goldbach Codes semua bilangan genap positif yang lebih besar dari 2 merupakan penjumlahan dari dua bilangan prima [15], [16]. Goldbach Codes yang pertama dinamakan G0. G0 mengkodekan bilangan bulat positif $\mathrm{n}$ dengan mengubahnya menjadi bilangan bulat positif genap dengan 2(n+3) dan kemudian menuliskan pasangan penjumlahan bilangan prima dalam keadaan terbalik [15].

Goldbach Codes kedua dinamakan G1. Prinsip G1 adalah menentukan dua bilangan prima $\mathrm{Pi}$ danPj (dimana $\mathrm{i} \leq \mathrm{j}$ ) yang jumlahnya menghasilkan bilangan bulat $\mathrm{n}$, dan mengkodekan pasangan (i.j-i+1) dengan gamma codes. Goldbach Codes yang ketiga dinamakan G2 adalah perluasan dari kode G1. Panjang kode G2 lebih sulit diperkirakan, tetapi pada eksperimen yang sederhana yang menghitung kode-kode ini untuk nilain n. Nilai dari 2 sampai 512 menunjukan bahwa panjangnya (yang mana seringkali bervariasi 2-3 bit dari kode ke kode) dapat didekati dengan kelancaran fungsi. Hal tersebut diperkuat dengan penelitian yang dilakukan Friedland, bahwa hasil utamanya adalah bahwa tidak ada bahkan n 8 di mana semua $n 1$ dapat ditambahkan dirumuskan tanpa memasukkan kasus penambahan dua bilangan prima. Hasil sampingnya adalah ganjil apapun bilangan bulat $\mathrm{n}$ dapat diwakili oleh 1 penambahan dari 2 bilangan prima jika dan hanya jika $n 2$ adalah bilangan prima [16].

Algoritma Goldbach code memiliki fungsi untuk mengkompresi (memperkecil), dan data yang telah terkompresi disematkan di dalam penyimpanan memori dan data menjadi lebih aman [15]. Untuk memperkuat penelitian ini maka didukung dengan penelitian terdahulu misalnya peningkatan kebutuhan terhadap data digital yang semakin hari semakin tinggi, menjadi tantangan yang cukup besar akan terbatasnya media penyimpanan (storage) [13]. Disisi lain aspek keamanan sangat diperhatikan mengingat rentannya pencuraian dan manipulasi terhadap sebuah data, penelitian lain [17]. Aplikasi dapat di gunakan dalam mengiventariskan produk yang ada pada stok stok di gudang yang meliputi pencatatan, pengolahan, dan pelaporan data data pada persediaan gudang. Dengan adanya Aplikasi berbasis web, kantor pusat dapat melihat laporan dari gudang dengan tepat sasaran, akurat, dan efisien. Adapun penelitian yang dilakukan oleh Almurtada, bahwa selain keamanan, hal yang perludi perhatikan juga adalah tentang memori penyimpanan, dengan menggunakan algoritma goldbach codes kita dapat memaksimalkan memori penyimpanan, karena dapat mengurangi ukuran file tersebut [18]. Sedangkan penelitian monitoring sistem inventori sangat dibutuhkan perusahaan yang bergerak dalam bidang penjualan barang dan jasa, yang mengutamakan mutu barang dan pelayanan konsumen [19]. Oleh karena itu, pengembangan sistem informasi inventori barang perlu mempertimbangkan aspek optimalisasi media penyimpanan. 
PT. Multi Usaha Sejahtera Jaya didirikan tahun 2015 merupakan perusahaan yang bergerak di bidang processing ikan, distributor yang menjual dengan harga standar sehingga banyak pelanggan ataupun agen yang membeli barang di PT. Multi Usaha Sejahtera Jaya. Untuk pengambilan barang produksi, perusahaan ini memasoknya dari Jawa. Salah satu supplier perusahaan ini dari Juwana [20]. Setiap barang yang datang atau yang masuk dari supplier (pemasok) dicek oleh kepala gudang yang mana supplier memberikan surat jalan kepada gudang untuk mengetahui jumlah dan jenis ikan apa saja yang dibawa. Setelah melakukan pengecekan kepala gudang baru kebagian kantor untuk menginformasikan barang yang masuk. Sedangkan untuk proses barang keluar pelanggan yang ingin memesan bisa mengajukan PO terlebih dahulu lewat email dan dapat datang langsung ke kantor. Pelanggan yang telah selesai melakukan transaksi di kantor, kemudian pelanggan datang ke bagian gudang untuk melihat barang tersebut dengan memberikan kwitansi barang yang dipesan kepada admin gudang untuk melakukan proses pengiriman barang. Penjualan barang terjadi setiap hari [20].

PT Multi Usaha Sejahtera Jaya selalu melakukan pengawasan dan pencatatan terhadap persediaan barang. Persediaan (Inventory) adalah barang dagangan yang dibeli untuk dijual kembali dan masih ada di gudang berupa stok [21]. Selama ini untuk pengolahan dan persediaan barang masih dilakukan secara manual oleh admin produksi yaitu untuk pendataan barang masuk dan keluar, data pengiriman barang dicatat di buku besar sesuai dengan kwitansi yang berisi berapa banyak barang yang masuk dan keluar untuk dikirim ke pelanggan. Pendataan stok barang hanya dicatat di buku yang mana laporan-laporan yang sudah ditulis oleh admin produksi tersebut akan disalin kembali ke komputer. Sehingga dari permasalahan tersebut terkadang terjadi kesalahan dalam perhitungan barang, kesulitan dalam pencatatan dan pembuatan laporan barang masuk dan keluar dari kwitansi atau surat jalan pelanggan yang banyak. Pada bulan-bulan tertentu terjadi kesulitan dalam pencarian data barang yang diperlukan karena penumpukan berkas yang banyak.

Beberapa penelitian terkait sistem inventory yaitu: (1) sistem informasi persediaan barang pada perusaan ekspor hasil laut [1]; (2) sistem informasi persediaan dan penjualan barang pada koperasi [3]; (3) sistem informasi persediaan barangg dengan metode Extreme Programming (XP) [4]; (4) sistem inventory barang digunakan untuk menekan kerugian barang kadaluwarsa dan meningkatkan efisiensi pencatatan persediaan barang menggunan sistem Rapid Application Development (RAD) [22]; (5) sistem manajemen nventory menggunakan framework EasyUI [23]; (6) sistem inventori barang menggunakan Data Flow Diagram (DFD) untuk pemodelan terstruktur [24]; (7) sistem inventori gudang [25]; dan (8) sistem inventori spart part elektronik [26]. Berbagai penelitian tersebut belum melakukan kompresi data. Artikel ini mendeskripsikan pengembangan sistem informasi inventori barang dengan menerapkan algoritma Goldbach Codes. Hal tersebut memiliki peran strategis dalam hal kemudahan pengelolaan dan optimalisasi media penyimpanan, sehingga transmisi data menjadi lebih baik.

\section{METODE}

Metodologi adalah kerangka teoritis yang digunakan oleh penulis untuk menganalisa, mengerjakan atau mengatasi masalah yang dihadapi. Sedangkan kerangka teoristis merupakan metode-metode ilmiah yang akan diterapkan dalam pelaksanaan tugas. Metode penelitian sangat penting karena baik-buruknya hasil penelitian tergantung dari metodologi penelitian yang digunakan. Adapun metode penelitian yang digunakan menggunakan metode R\&D. Metode penelitian Research and Development (R\&D) adalah metode penelitian yang digunakan untuk menghasilkan produk tertentu dan menguji keefektifan produk tersebut. Untuk menghasilkan produk tertentu digunakan penelitian yang bersifat analisis kebutuhan dan untuk menguji keefektifan 
produk tersebut supaya dapat berfungsi di masyarakat luas [27], maka diperlukan penelitian untuk menguji keefektifan produk tersebut. Dalam proses penelitian ini penulis hanya meggunakan 7 langkah dalam metode R\&D dikarenakan waktu dan biaya yang terbatas. Berikut langkah - langkah metode R\&D. Gambar 1 merupakan diagram pelaksanaan tiap langkah dalan metode $R \& D$ yang digunakan dalam artikel ini.

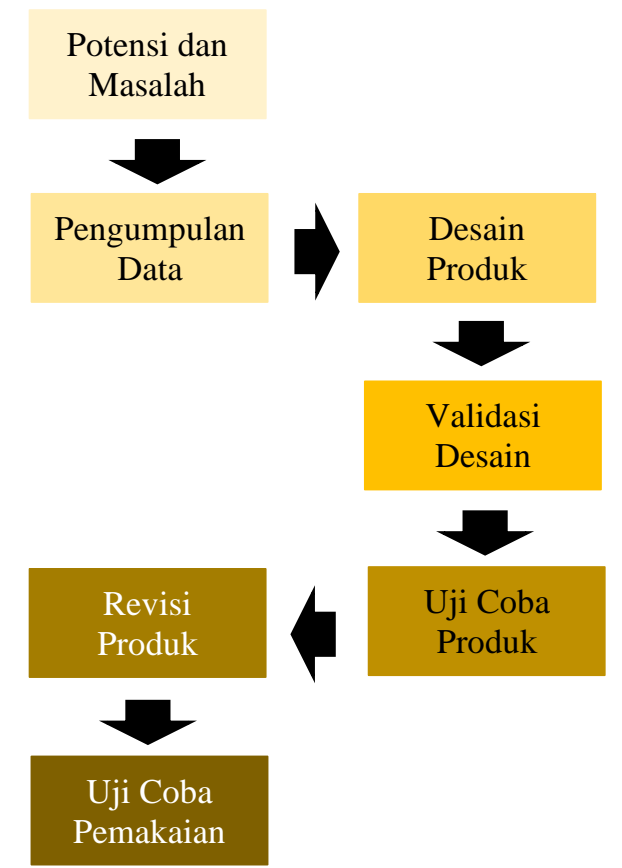

Gambar 1. Metode Research and Development (R\&D) 7 Langkah pada pengembangan sistem inventori di PT Multi Usaha Sejahtera Jaya

Penulis melakukan penelitian di PT Multi Usaha Sejahtera Jaya pada bulan Februari-Maret pada tahun 2019. Karena pada bulan-bulan itu banyak kapal yang melaut sehingga kemungkinan perusahaan akan mendapatkan stok ikan yang banyak. Berbeda dari bulan november-desember, karena pada bulan-bulan itu pelaut banyak yang pulang dengan alasan tahun baru. Apabila di bulan April banyak pelaut yang tidak berani melaut karena ombak yang besar yang disertai angin. Biasanya para pelaut menyebutnya dengan baratan. Sehingga perusahaan bisa mengambil stok barang pada bulan Februari-Maret dengan sebanyakbanyaknya.

\section{HASIL DAN PEMBAHASAN}

Pada tahap potensi dan masalah, penulis melakukan penelitian di PT Multi Usaha Sejahtera Jaya. Dalam melakukan penelitian di tempat tersebut penulis menemukan masalah yang dihadapi oleh PT Multi Usaha Sejahtera Jaya ini yaitu belum memiliki sistem penyimpanan stok barang berbasis website [20]. Oleh karena itu, penulis bermaksud mengembangkan sistem penyimpanan stok barang berbasis website. Hal tersebut bertujuan untuk memudahkan admin serta pelanggan untuk mengakses penjualan secara online dan juga bisa melakukan pencatatan data secara terkomputerisasi tanpa membung-buang kertas.

Data yang dihimpun pada tahapan pengumpulan data berupa literasi dari buku mengenai inventori stok, wawancara dan observasi terhadap pegawai dan manajer yang mengurusi stok barang di PT Multi Usaha Sejahtera Jaya. Pada tahap desain produk penulis melakukan desain pembuatan sistem penyimpanan stok barang berbasis web yang akan diuji coba dan juga diterapkan di PT Multi Usaha Sejahtera Jaya. Penulis merancang desain sesuai dengan kebutuhan manajer dan admin stok barang agar informasi pada tampilan aplikasi sesuai dengan harapan.

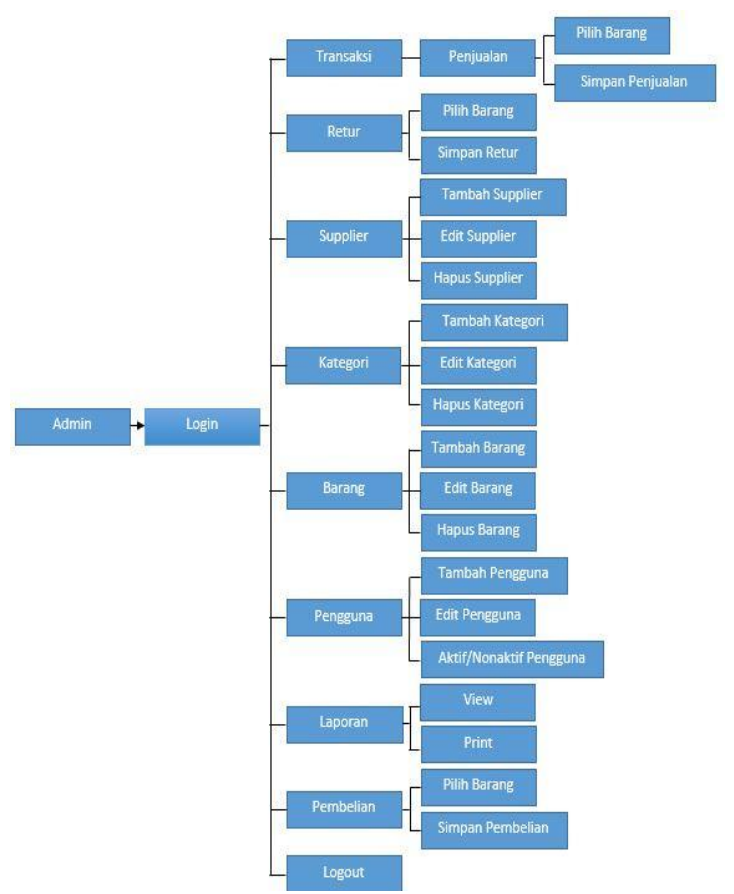

Gambar 2. Perancangan sistem inventory stok 
Gambar 2 merupakan perancangan produk sistem inventori yang dikembangkan. Perancangan produk dalam penelitian ini dilakukan berdasar anlisis potensi dan masalah serta pengumpulan data di tempat penelitian. Model use case menjelaskan mengenai aktoraktor yang terlibat dengan perangkat lunak yang di bangun beserta proses-proses yang ada di dalamnya. Gambar 3 menunjukkan use case diagram. Activity Diagram adalah salah satu cara untuk memodelkan aktivitas yang terjadi dalam suatu aplikasi Berikut ini activity diagram dari website inventory PT Multi Usaha Sejahtera Jaya. Activity diagram tersaji pada Gambar 4.

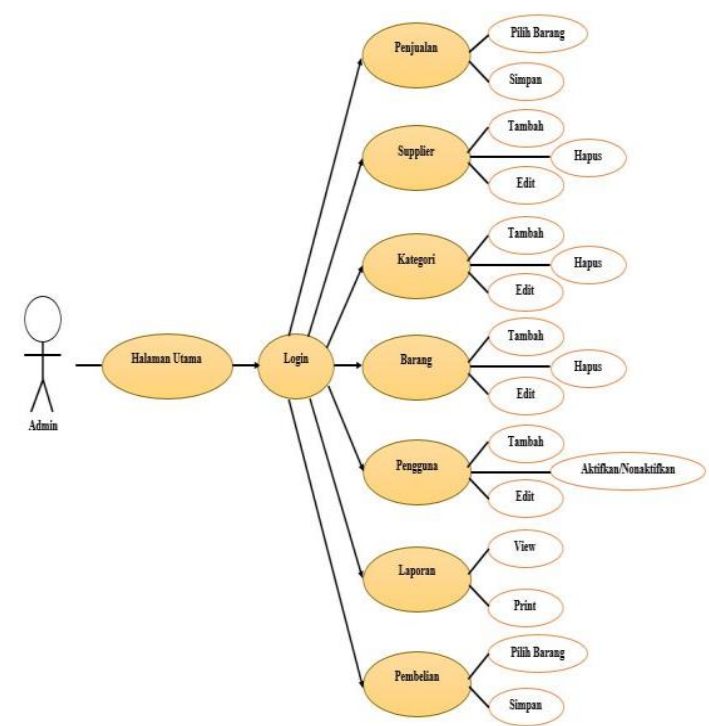

Gambar 3. Use case diagram

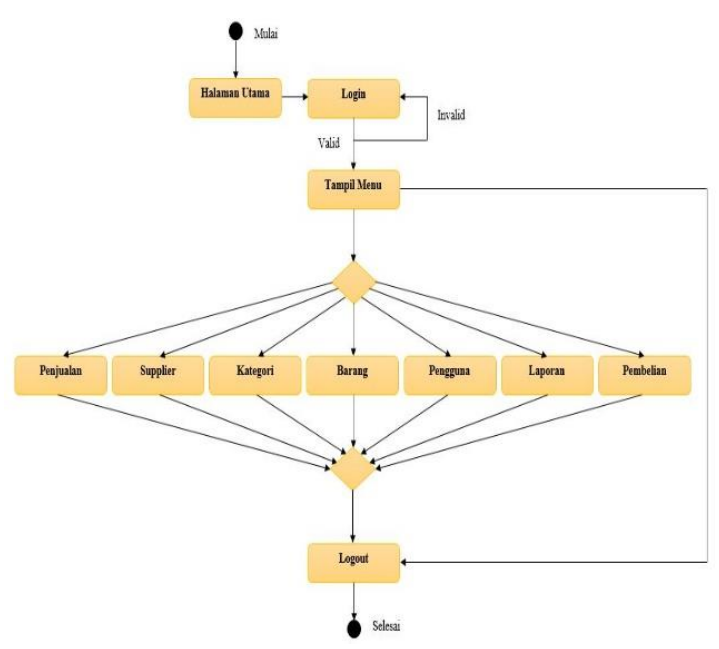

Gambar 4. Activity diagram
Terdapat beberapa tabel pada database yang dirancang pada pengembangan sistem ini. Tabel tersebut diantaranya adalah tabel user, supplier, kategori, barang, beli, detail beli, jual, detail jual, dan retur. Contoh tabel database tersebut ditunjukkan pada Tabel 1. Selanjutnya untuk melihat relasi antar entitas dalam aktivitas pemodelan data dirancang Entity Relationship Diagram (ERD). ERD inventori stok barang PT. Multi Usaha Sejahtera Jaya dapat dilihat pada Gambar 5.

Tabel 1. Tabel detail jual

\begin{tabular}{|c|c|c|}
\hline Nama Field & Tipe & Keterangan \\
\hline d_jual_id & $\operatorname{Int}(11)$ & $\begin{array}{l}\text { Primarykey untuk id } \\
\text { jual }\end{array}$ \\
\hline d_jual_nofak & $\begin{array}{l}\text { Varchar } \\
(15)\end{array}$ & $\begin{array}{l}\text { Field untuk nomor } \\
\text { faktur jual }\end{array}$ \\
\hline d_jual_barang & $\begin{array}{l}\text { Varchar } \\
(15)\end{array}$ & $\begin{array}{l}\text { Field untuk id barang } \\
\text { penjualan }\end{array}$ \\
\hline $\begin{array}{l}\text { d_jual_barang } \\
\text { _nama }\end{array}$ & $\begin{array}{l}\text { Varchar } \\
(150)\end{array}$ & $\begin{array}{l}\text { Field untuk nama } \\
\text { barang yang dijual }\end{array}$ \\
\hline $\begin{array}{l}\text { d_jual_barang } \\
\text { _satuan }\end{array}$ & $\begin{array}{l}\text { Varchar } \\
(30)\end{array}$ & $\begin{array}{l}\text { Field untuk satuan } \\
\text { barang yang dijual }\end{array}$ \\
\hline $\begin{array}{l}\text { d_jual_barang } \\
\text { _harpok }\end{array}$ & Double & $\begin{array}{l}\text { Field untuk harga } \\
\text { pokok barang yang } \\
\text { dijual }\end{array}$ \\
\hline $\begin{array}{l}\text { d_jual_barang } \\
\text { _harjul }\end{array}$ & Double & $\begin{array}{l}\text { Field untuk harga jual } \\
\text { barang yang dijual }\end{array}$ \\
\hline $\bar{d}$ d_jual_qty & $\operatorname{Int}(11)$ & $\begin{array}{l}\text { Field untuk quantity } \\
\text { jual }\end{array}$ \\
\hline d_jual_diskon & Double & Field untuk diskon \\
\hline d_jual_total & Double & $\begin{array}{l}\text { Field untuk total } \\
\text { barang yang dijual }\end{array}$ \\
\hline
\end{tabular}

Desain interface merupakan rancangan antarmuka yang akan digunakan sebagai perantara user dengan perangkat lunak yang akan dikembangkan. Desain tersebut menampilkan beberapa fitur pada aplikasi, yaitu halaman muka, halaman login, halaman menu, halaman penjualan, halaman supplier, halaman kategori, halaman barang, halaman pengguna, halaman pembelian, dan halaman laporan. Desain antarmuka dari website inventory untuk halaman utama terssaji pada Gambar 6 dan laporan tersaji pada Gambar 7. 


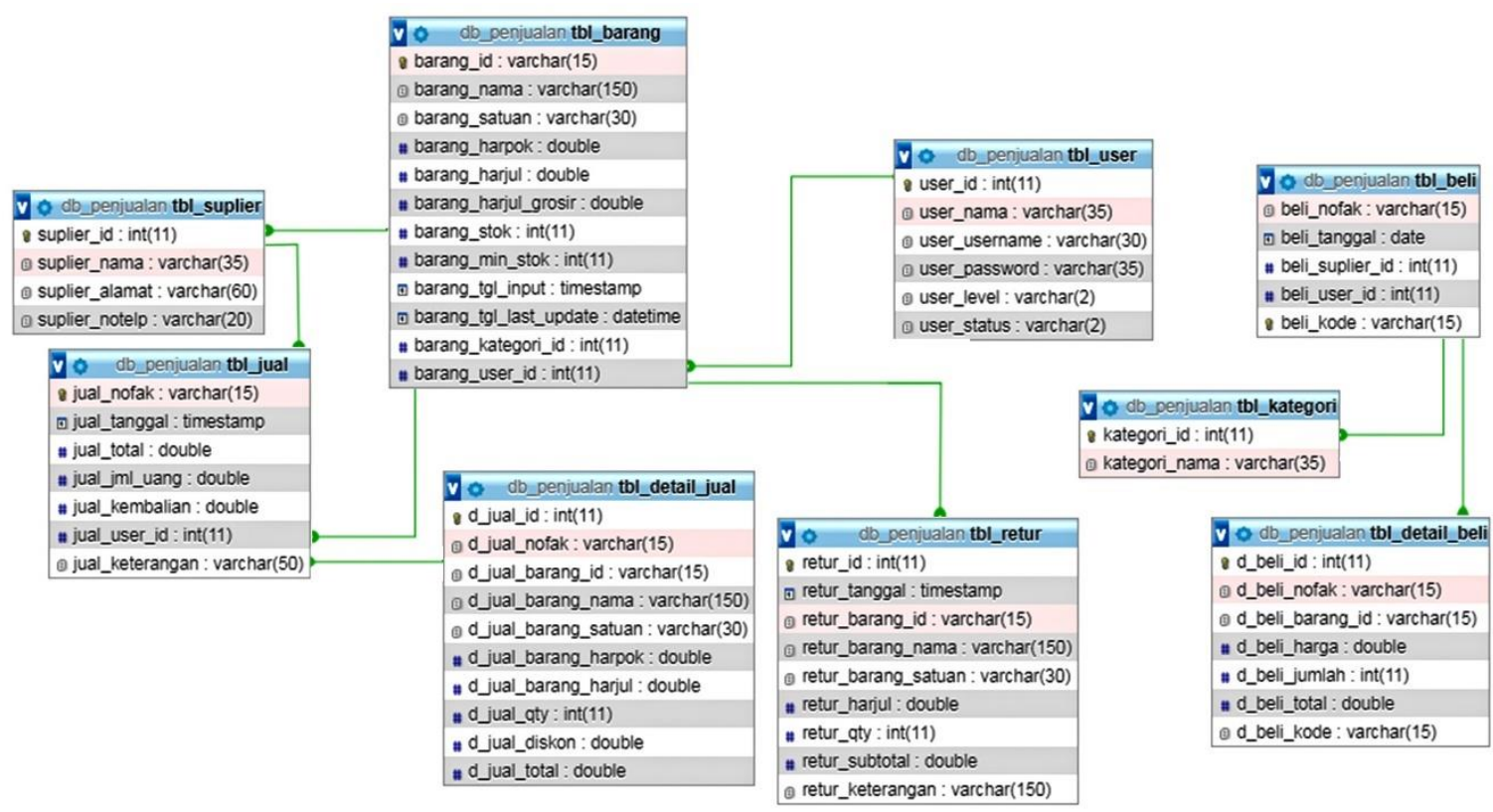

Gambar 5. ERD inventori stok barang PT. Multi Usaha Sejahtera Jaya

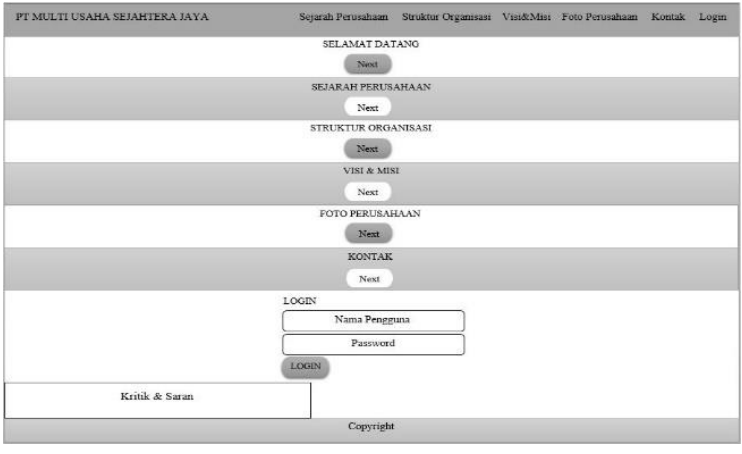

Gambar 6. Desain antarmuka halaman utama

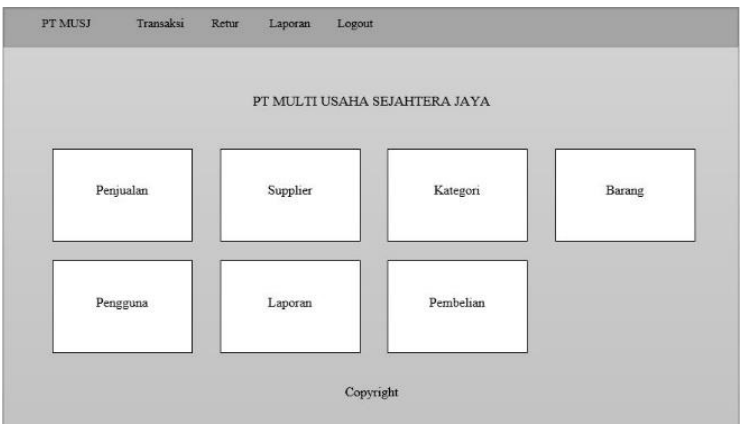

Gambar 7. Desain antarmuka halaman

Setelah perancangan desain aplikasi selesai, dilakukan validasi desain. Dalam tahap validasi desain dilakukan uji validasi yang dilakukan oleh manajer PT Multi Usaha Sejahtera Jaya dan ahli IT. Validasi dilakukan untuk mengetahui kesesuaian desain sistem inventori dengan kebutuhan informasi dan penggunaan di PT Multi Usaha Sejahtera Jaya. Instumen yang dilakukan berupa angket dan lembar saran.
Validasi desain bertujuan untuk menilai kelayakan desain tampilan dan fitur aplikasi penyimpanan. Penilaian berfokus pada tampilan mudah digunakan atau tidak, menu-menu, fitur, Transaksi, retur, laporan, penjualan, suplier, kategori, barang. Kemudian kemudahan menggunakan aplikasi inventory stok barang. Pada tahap uji coba produk dilakukan uji coba terhadap produk yang telah dihasilkan yaitu dengan uji sistem penyimpanan stok barang berbasis web pada PT Multi Usaha Sejahtera Jaya. Adapun kriteria penilaian hasil uji coba ada pada Tabel 2.

Tabel 2. Kriteria Penilaian

\begin{tabular}{ll}
\hline Kriteria Penilaian & Presentase \\
\hline Sangat layak & $81 \%-100 \%$ \\
Layak & $61 \%-80 \%$ \\
Kurang Layak & $41 \%-60 \%$ \\
Tidak Layak & $21 \%-40 \%$ \\
Sangat Tidak Layak & $0 \%-20 \%$ \\
\hline
\end{tabular}

Validasi aplikasi inventori stok dilakukan secara terbatas yaitu diwakili oleh manajer dan admin PT. Multi Usaha Sejahtera Jaya. Validasi pengguna ini memiliki tujuan menilai aplikasi dalam penggunaan dan kemudahan dalam mengoprasikan aplikasi inventory stok. Aspek yang dinilai antara lain tampilan aplikasi menumenu pada sistem inventori yang dikembangkan. 
Hasil penilaian dari ahli IT sebesar $83 \%$ pada aspek desain dan tampilan. Sedangkan pada aspek fitur dan menu sebesar $82 \%$. Saran yang diberikan para ahli adalah (1) tampilan disesuaikan dengan tema perusahaan ikan; (2) ditambah loading bar saat menu proses penyimpanan atau mencetak laporan; (3) menambah menu cetak laporan per cek poin. Validasi memiliki tujuan untuk menilai desain dan menu-menu sudah berfungsi dengan baik tanpa adanya eror.

Hasil penilaian dari Manajer dan admin PT. Multi Usaha Sejahtera Jaya sebesar $85 \%$ pada aspek desain dan tampilan. Sedangkan pada aspek fitur dan menu sebesar $85 \%$. Masukan yang diberikan oleh manajer dan admin adalah (1) penambahan tata cara penggunaan aplikasi pada halaman utama; (2) menambah keterangan pada proses penyimpanan. Hasil validasi manajer dan admin menjadi bahan perbaikan dalam tahap revisi desain. Gambar 8 menunjukkan tahapan penilaian uji coba produk.

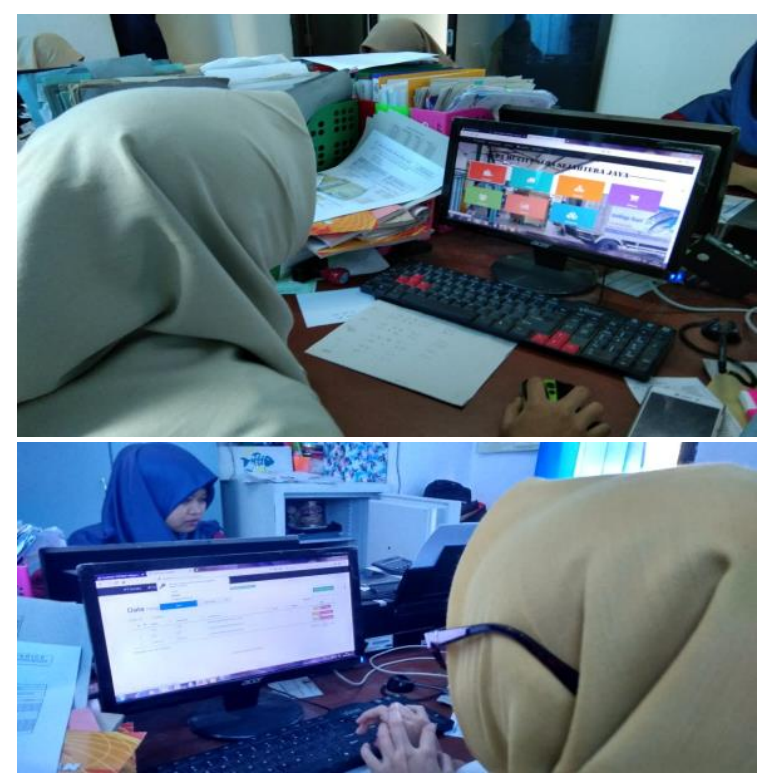

Gambar 8. Uji coba produk

Pada tahap revisi produk, semua kritikan dari manajer dan admin PT Multi Usaha Sejahtera Jaya ditampung kemudian akan dilakukan revisi atau perbaikan dari produk tersebut. Adapun terdapat beberapa masalah eror pada aplikasi ketika menyimpan data sehingga hal tersebut diperbaiki pada tahap revisi produk ini. Jika tidak ada lagi error pada aplikasi maka dilakukan tahap uji pemakaian lanjutan. Setelah perbaikan dilakukan pengujian akhir produk, jika tidak ditemukan masalah maka aplikasi inventory stok dinyatakan berhasil, maka sistem penyimpanan stok barang berbasis web tersebut akan diterapkan oleh PT Multi Usaha Sejahtera Jaya untuk mempermudahkan proses penyimpanan barang.

Setelah melakukan perbaikan atau revisi terhadap beberapa fitur dari sistem informasi inventory stok barang. Dilakukan uji coba pemakaian akhir dengan hasil akhir tidak ada eror pada aplikasi dengan tampilan Beranda Sistem Inventory Stok Barang pada PT. Multi Usaha Sejahtera Jaya. Hasil uji coba pemakaian dapat dilihat pada Tabel 3.

Tabel 3. Uji Pemakaian

\begin{tabular}{cccc}
\hline $\begin{array}{c}\text { Uji } \\
\text { Pemakaian }\end{array}$ & Tanggal & Fitur yang di uji & $\begin{array}{c}\text { Temuan } \\
\text { masalah }\end{array}$ \\
\hline Uji Pertama & 15 April & Transaksi, & Tidak \\
& 2019 & retur, laporan & ada \\
Uji Kedua & 16 April & Penjualan, & Tidak \\
& 2019 & suplier, & Ada \\
& & kategori, barang & \\
\hline
\end{tabular}

Terdapat sejarah perusahaan, struktur organisasi, visi misi, foto, kontak dan login. Tampilan Menu utama dapat dilihat pada Gambar 9. Login Bagian menu untuk masuk ke dalam sistem inventory-nya. Isikan Username dan Password. Kategori menu untuk mengisikan kategori dari macam-macam barang. Menu supplier yaitu menu untuk menambahkan supplier atau pemasok kedalam website. Tampilan menu tersebut dapat dilihat pada Gambar 10. Menu Barang ini digunakan untuk menambahkan barang dan melihat stok barang. Menu Pengguna yang dapat login kedalam website inventory. Menu pembelian digunakan untuk menambah stok barang yang baru dibeli. Menu Penjualan berisi kegiatan melakukan transaksi penjualan kepada pelanggan oleh admin yang sudah login. Menu laporan melihat laporan transaksi yang telah dilakukan dan mencetaknya. Menu laporan dapat dilihat pada Gambar 11. 


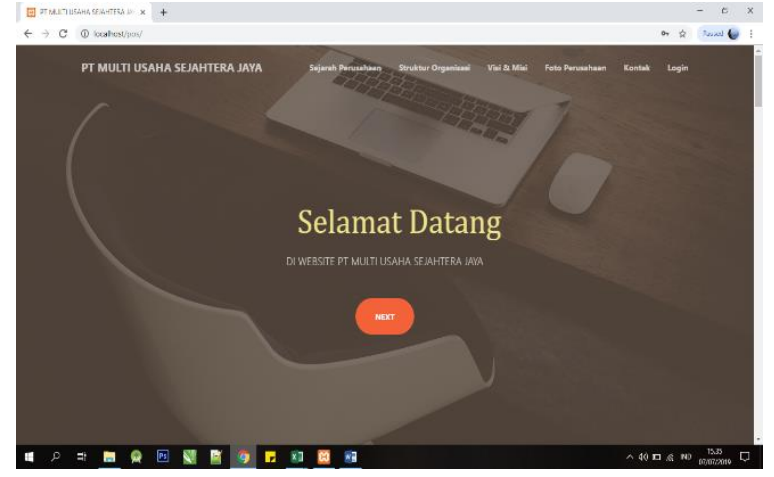

Gambar 9. Halaman Utama Inventori Stok

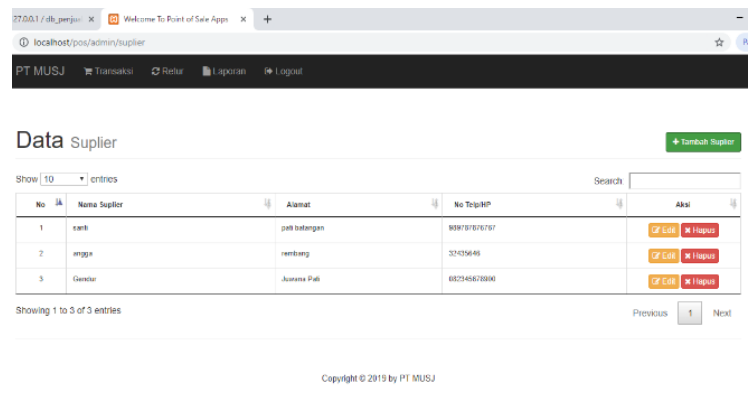

Gambar 10. Halaman menu supplier

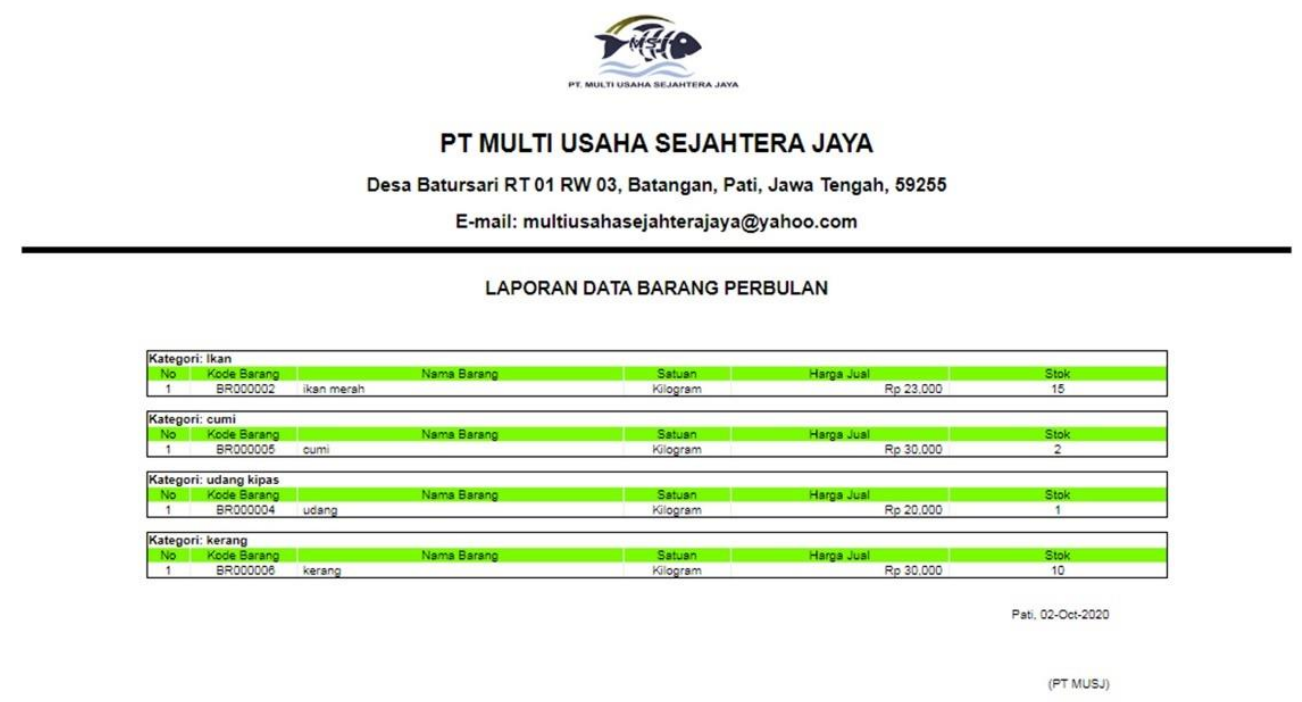

Gambar 11 Laporan Data barang

Tahapan pengujian awal sebelum menerapkan aplikasi penyimpanan stok barang adalah menerapkan algoritma Goldbach Codes yaitu suatu metode untuk meminimalisir penggunaan memori penyimpanan pada database MSQL, apakah dalam teori tersebut benar benar mampu mengkompresi data. Untuk memperkuat pembahasan maka penulis mengkaji bebera penelitian diantaranya yang dilakukan oleh Budiman yang menyatakan bahwa memori penyimpanan tidak cepat penuhketika menggunakan algoritma Goldbach Codes [28]. Penulis juga menemukan bukti bahwa Goldbach Codes yang diterapkan dalam aplikasi penyimpanan inventory stock mampu membuat data menjadi lebih kecil dalam ukuran penyimpanan dalam bit. hal ini diperkuat dalam penelitian lain yang menggunakan konsep dasar untuk menjelaskan dan secara tidak langsung demi membuktikan dugaan Goldbach. dalam membuktikan teorema $1+2$ untuk kompresi data [29].

Penerapan algoritma Goldbach Codes untuk mengkompresi file teks, maka penulis mengambil sample text yang mana nanti akan di proses menggunakan algoritma Golbach Codes, data hasil akan ditampilkan dibawah. Langkah pertama dilakukan dengan membaca isi file teks tersebut. Format file teks yang digunakan dalam penelitian ini yaitu file dengan eksteksi ".txt" dan isi file tersebut yang nantinya akan di kompresi dan disimpan menjadi dua file yang baru yaitu file hasil kompresi dan file header yang menjadi kunci untuk melakukan dekompresi. Misalkan isi file teks tersebut adalah "SURYA DARMA NASUTION", 
proses kompresinya dapat dilihat pada Tabel 4 . Hasil kompresi menggunakan algoritma Goldbach Codes dapat dilihat pada Tabel 5.

Tabel 2. Data Sebelum dikompresi

\begin{tabular}{cccccc}
\hline Char & Freq & $\begin{array}{c}\text { ASCII } \\
\text { Desimal }\end{array}$ & ASCII Binary & Bit & $\begin{array}{c}\text { Bit x } \\
\text { Freq }\end{array}$ \\
\hline $\mathrm{S}$ & 2 & 83 & 01010011 & 8 & 16 \\
$\mathrm{U}$ & 2 & 85 & 01010101 & 8 & 16 \\
$\mathrm{R}$ & 2 & 82 & 01010010 & 8 & 16 \\
$\mathrm{Y}$ & 1 & 89 & 01011001 & 8 & 8 \\
$\mathrm{~A}$ & 4 & 65 & 01000001 & 8 & 32 \\
$\mathrm{Sp}$ & 2 & 32 & 00100000 & 8 & 16 \\
$\mathrm{D}$ & 1 & 68 & 01000100 & 8 & 8 \\
$\mathrm{M}$ & 1 & 77 & 01001101 & 8 & 8 \\
$\mathrm{~N}$ & 2 & 78 & 01001110 & 8 & 16 \\
$\mathrm{~T}$ & 1 & 84 & 01010100 & 8 & 8 \\
$\mathrm{I}$ & 1 & 73 & 01001001 & 8 & 8 \\
$\mathrm{O}$ & 1 & 79 & 01001111 & 8 & 8 \\
& jumlah bit x frequency & & 160 \\
\hline
\end{tabular}

Tabel 3. Data Sesudah dikompresi

\begin{tabular}{cccccccc}
\hline Char & Freq & $\mathrm{N}$ & $\begin{array}{c}2 \\
(\mathrm{n}+3)\end{array}$ & $\begin{array}{c}\text { bil. } \\
\text { prima }\end{array}$ & $\begin{array}{c}\text { code } \\
\text { word }\end{array}$ & $\begin{array}{c}\text { Bit } \\
\text { Fit } \mathrm{x} \\
\text { Freq }\end{array}$ \\
\hline $\mathrm{A}$ & 4 & 1 & 8 & $3+5$ & 11 & 2 & 8 \\
$\mathrm{~S}$ & 2 & 2 & 10 & $3+7$ & 101 & 3 & 6 \\
$\mathrm{U}$ & 2 & 3 & 12 & $5+7$ & 001 & 3 & 6 \\
$\mathrm{R}$ & 2 & 4 & 14 & $3+11$ & 011 & 4 & 8 \\
$\mathrm{Sp}$ & 2 & 5 & 16 & $5+11$ & 1001 & 4 & 8 \\
$\mathrm{~N}$ & 2 & 6 & 18 & $7+11$ & 0101 & 4 & 8 \\
$\mathrm{Y}$ & 1 & 7 & 20 & $7+13$ & 0011 & 5 & 5 \\
$\mathrm{D}$ & 1 & 8 & 22 & $5+17$ & 010001 & 6 & 6 \\
$\mathrm{M}$ & 1 & 9 & 24 & $11+13$ & 00011 & 5 & 5 \\
$\mathrm{~T}$ & 1 & 10 & 26 & $7+9$ & 0010001 & 7 & 7 \\
$\mathrm{I}$ & 1 & 11 & 28 & $11+7$ & 000101 & 6 & 6 \\
$\mathrm{O}$ & 1 & 12 & 30 & $11+7$ & 000011 & 6 & 6 \\
& & \multicolumn{7}{c}{ jumlah bit x frequency } & 79 \\
\hline
\end{tabular}

Langkah selanjutnya adalah menyusun kembali kode-kode yang telah dibuat pada tabel sesuai dengan posisi karakter pada string. String yang telah dibaca dari file teks adalah "SURYA DARMA NASUTION", Sehingga diperoleh string bit sebagai berikut.

\section{0 10100111110101100100010001010000110011}

Pada proses dekompresi dilakukan pembacaan pada string bit yang diperoleh pada proses kompresi terhadap Tabel 4. Pembacaan string bit dilakukan dari indeks terkecil sampai indeks terakhir dengan terus menambahkan nilai pada indeks sebelumnya yang tidak mewakili karakter pada Tabel 4. Teknik kompresi Goldbach Codes diterapkan pada pengembangan sistem inventori ini. Algoritma Goldbach Codes digunakan untuk menuntuk mengkompresi file teks agar lebih kecil dalam penyimpanan sehingga memori aplikasi yang dipakai lebih hemat. Dengan hasil pengujian sederhana algoritma Goldbach codes mampu menghemat 81 bit data dari 160 bit data yang masuk pada database sehingga didapat hasil 49 $\%$ mampu menghemat pemakaian memori penyimpanan data pada aplikasi inventory stok barang pada PT. Multi Usaha Sejahtera Jaya.

Dengan terwujudnya sistem inventori stok ini, harapan implementasinya adalah sesuai dengan penelitian-penelitian sebelumnya yang menyatakan bahwa aplikasi inventori stok akan meningkatkan penyimpanan data dan pencarian data lebih mudah serta paperless. Hasil penilaian pada tahap uji coba produk menunjukkan bahwa sistem inventori sangat layak digunakan. Tambahan hasil uji coba pemakaian akhir menunjukkan bahwa tidak ada eror pada aplikasi. Hasil penilaian-penilain tersebut menunjukkan bahwa sistem inventori tersebut dapat diimplementasikan. Penelitian ini dapat dijadikan pijakan untuk penelitian terkait. Aspek yang perlu dipertimbangkan pada penelitian ke depan adalah keberterimaan sistem informasi. Keberterimaan tersebut terkait dengan aspek kemudahan dan kenyamanan pengguna dalam menggunakan sistem. Salah satu yang bisa digunakan untuk menilai aspek tersebut adalah TAM. Hal tersebut sejalan 
dengan penelitian yang dilakukan Nurfiyah et al bahwa analisis TAM dapat digunakan untuk mengetahui perspesi pengguna terkait kemudahan dan kenyamanan penggunaan sistem [30].

\section{SIMPULAN}

Dari penilaian kuisioner diperoleh $83 \%$ sangat layak dari ahli IT, $85 \%$ pegawai PT. Multi Usaha Sejahtera Jaya. Dapat disimpulkan bahwa aplikasi inventory stok barang yang telah dikembangkan "sangat layak". Pengembangan aplikasi inventory stok memberikan implikasi (1) dapat meminimalisir kesalahan yang bisa terjadi apabila sistem masih dilakukan secara manual. (2) dapat mempercepat waktu proses persediaan barang masuk dan keluar, penyimpanan data lebih terstruktur dan rapi, (3) tidak membutuhkan banyak tempat dalam penyimpanan, dan meminimalisir penggunaan kertas (paperless). Sehingga pada tahun 2019 diharapkan dapat mempermudah pekerjaan PT. Multi Usaha Sejahtera Jaya dalam mengelola data barang.

Algoritma Goldbach Codes digunakan untuk menuntuk mengkompresi file teks agar lebih kecil dalam penyimpanan sehingga memori aplikasi yang dipakai lebih hemat. Dengan hasil pengujian sederhana algoritma Goldbach codes mampu menghemat 81 bit data dari 160 bit data yang masuk pada database sehingga didapat hasil $49 \%$ mampu menghemat pemakaian memori penyimpanan data pada aplikasi inventory stok barang pada PT. Multi Usaha Sejahtera Jaya. Saran untuk pengembangan aplikasi inventory stok selanjutnya adalah: (1) tampilan disesuaikan dengan tema perusahaan ikan; (2) ditambah loading bar saat menu proses penyimpanan atau mencetak laporan; dan (3) menambah menu cetak laporan per cek poin. Dalam mengembangkan inventory stok juga memperhatikan kemampuan hardware dan software yang dimiliki agar dalam pengembangan dapat berjalan dengan maksimal.

\section{DAFTAR PUSTAKA}

[1] B. Arifudzaki, M. Somantri, and A. FR, "Aplikasi Sistem Informasi Persediaan Barang pada Perusahaan Ekspor Hasil Laut Berbasis Web," Transmisi, vol. 12, no. 4, pp. 138-144, 2010.

[2] F. Andalia and E. B. Setiawan, "Pengembangan Sistem Informasi Pengolahan Data Pencari Kerja pada Dinas Sosial dan Tenaga Kerja Kota Padang," J. Ilm. Komput. dan Inform., vol. 4, no. 2, pp. 93-98, 2015.

[3] Rosdiana, E. D. Rahmawati, and M. Susilowati, "Sistem Informasi Persediaan Dan Penjualan Barang Berbasis Web Pada Koperasi Kosma 15," in Konferensi Nasional Sistem \& Informatika, 2015, pp. 915-920.

[4] R. Priskila, "Perancangan Sistem Informasi Persediaan Barang Pada Perusahaan Karya Cipta Buana Sentosa Berbasis Web dengan Metode Extreme Programing," Comput. Eng. Sci. Syst. J., vol. 3, no. 2, p. 94, Aug. 2018.

[5] B. Dengan and M. Metode, "Aplikasi perhitungan stok barang di waserda koperasi unit desa minarasa batukaras dengan menggunakan metode average."

[6] S. Assauri, Manajemen operasi produksi: pencapaian sasaran organisasi berkesinambungan, 3rd ed. Jakarta: PT. Raja Grafindo Persada, 2016.

[7] N. Sohail and T. H. Sheikh, "A Study of Inventory Management System Case Study," Jour Adv Res. Dyn. Control Syst., vol. 10, pp. 1176-1190, 2018.

[8] T. Nasution, "Optimalisasi Cloud Storage untuk Aksesbilitas Data Image pada Mobile Apps di STMIK AMIK Riau," JOISIE (Journal Inf. Syst. Informatics Eng., vol. 4, no. 1, p. 29, Jun. 2020.

[9] S. D. Nasution, "Perancangan Aplikasi Kompresi File Teks Menerapkan Algoritma Goldbach Codes," J. Infotek STIEKOM, vol. 1, no. 1, 2016.

[10] Y. Laia and M. Turnip, "Optimasi Rasio Kompresi Dan Kompleksitas Waktu Kompresi File Teks menggunakan Algoritma Lempel-ZIVWelch dengan Fibonacci Search," Sink. J. Penelit. Tek. Inform., vol. 1, no. 1, pp. 61-66, 2016.

[11]V. Lusiana, "Teknik Kompresi Citra Digital untuk Penyimpanan File menggunakan Format Data XML," J. Teknol. Inf. Din., vol. 19, no. 2, pp. 112-119, 2014.

[12] A. S. Laswi, "Pemanfaatan Algoritma Rice Codes dan Gold Bach Codes untuk Mengoptimalkan Media Penyimpanan pada Memori berupa File Text," J. INSTEK (Informatika Sains dan Teknol., vol. 4, no. 2, pp. 191-200, 2019.

[13]M. Yogie, "Penerapan Algoritma Goldbach Codes Pada Kompresi File Gambar Terenkripsi Vigenere Cihper," J. Pelita Inform., vol. 7, no. 1, pp. 81-85, 2018. 
[14] S. Nainggolan, “Analisa Perbandingan Algoritma Goldbach Codes Dengan Algoritma Dynamic Markov Compression (DMC) Pada Kompresi File Teks Menggunakan Metode Eksponensial," Maj. Ilm. INTI, vol. 6, no. 3, pp. 395-399, 2019.

[15] J. C. T. Arroyo and A. J. P. Delima, "LSB image steganography with data compression technique using goldbach G0 code algorithm," Int. J. Emerg. Trends Eng. Res., vol. 8, no. 7, pp. 32593264, 2020.

[16] Gerald Friedland, "On the Goldbach conjecture," Int. J. Pure Appl. Math., vol. 77, no. 3, pp. 289317, 2018.

[17]H. Agusvianto, "Sistem informasi inventori gudang untuk mengontrol persediaan barang," Journal Infrmation Engineering and Educational Technology, vol. 01, no. 012017. pp. 40-46, 2017.

[18]M. S. Ismail Almurtada, "Penerapan Algoritma Goldbach Codes pada Kompresi File Gambar Terenkripsi Vigenere Cihper," Pelita Inform. Budi Darma, vol. 6, no. April, pp. 473-478, 2018.

[19] J. Junaidi, R. Arifin, and A. Septiani, "Rancang Bangun Aplikasi Sistem Inventory Berbasis Desktop Menggunakan JSE," Konf. Nas. Sist. dan Inform., vol. 0, no. 0, pp. 846-850, 2015.

[20]A. D. Frayudha, Wawancara: Responden Kasnadi seorang General Manager (GM) PT. Multi Usaha Sejahtera Jaya. Pati, Jawa Tengah, 2019.

[21]F. Rangkuti, Bussiness Plan Teknik Membuat Perencanaan Bisnis \& Analisis Kasus. Jakarta: Gramedia Utama, 2005.

[22] S. Zalukhu, "Analisa dan Perancangan Aplikasi Sistem Inventory (Studi Kasus: PT. Cakra Medika Utama)," JSAI (Journal Sci. Appl. Informatics), vol. 2, no. 1, Jan. 2019.
[23] A. Bari and K. Kasmawi, "Sistem Informasi Manajemen Inventory Secara Online Menggunakan Framework EasyUI," INOVTEK Polbeng - Seri Inform., vol. 1, no. 1, p. 78, Jun. 2016.

[24]M. Hasanudin, "Rancang Bangun Sistem Informasi Inventori Barang Berbasis Web (Studi Kasus PT. Nusantara Sejahtera Raya)," J. IKRATH Inform., vol. 2, no. 3, pp. 24-37, 2018.

[25]H. Agusvianto, "Sistem Informasi Inventori Gudang Untuk Mengontrol Persediaan Barang Pada Gudang Studi Kasus : PT.Alaisys Sidoarjo," J. Inf. Eng. Educ. Technol., vol. 1, no. 1, p. 40, Mar. 2017.

[26] M. B. Rahmad and T. Setiady, "Perancangan Sistem Informasi Inventory Spare Part Elektronik Berbasis Web PHP (Studi CV. Human Global Service Yogyakarta)," J. Sarj. Tek. Inform., vol. 2, no. 2, pp. 256-265, 2014.

[27]Sugiyono, Metode Penelitian Kuantitatif, Kualitatif, dan R\&D. Bandung: Alfabeta, 2017.

[28]M. A. B. and D. Rachmawati, "Preface: International Conference on Recent Trends in Physics (ICRTP 2016)," J. Phys. Conf. Ser., vol. 755, no. 1, 2016.

[29]C. Liu, C. C. Chang, Z. P. Wu, and S. L. Ye, “A study of relationship between RSA public key cryptosystem and Goldbach's conjecture properties," Int. J. Netw. Secur., vol. 17, no. 4, pp. 445-453, 2015.

[30] Nurfiyah, N. A. Mayangky, S. Hadianti, and D. Riana, "Analisis Tachnology Acceptance Model pada Aplikasi Platform Perdagangan Elektronik di Kalangan Mahasiswa," J. Tek. Inform., vol. 12, no. 1, pp. 59-68, 2019. 